\title{
Аукцион резервирования мест доступа в заповедниках: теоретическое и экспериментальное исследование
}

\author{
Диана Авдеева, Александр Филатов ${ }^{*}$ \\ Дальневосточный федеральный университет, Владивосток, Россия
}

\author{
Информация о статье \\ Поступила в редакиию: \\ 20.03.2020 \\ Принята \\ к опубликованию: \\ 16.04.2020 \\ УДК 330.42 \\ JEL Q57, D44, C91
}

Ключевые слова:

заповедники, туризм, дизайн экономического механизма, аукционы, экспериментальная экономика

\section{Keywords:}

reserves, tourism, mechanism design, auctions, experimental economics

\begin{abstract}
Аннотация
Работа посвящена разработке эффективного механизма взаимодействия заповедников с туроператорами, который позволяет находить финансирование для приоритетных проектов, а также привлекать на рынок новых участников и создавать новые туристические продукты для потенциальных клиентов. Существующая схема распределения, препятствующая входу на рынок новичков, не позволяет раскрыть потенциал экологического и познавательного туризма. Предложенный механизм, главной составляющей которого является аукиион мест доступа, решает проблему неэффективности. В то же время, нерациональное поведение экономических агентов может нивелировать общественный выигрыш от аукииона. Пилотная серия экспериментов, проведенных как на студентах-экономистах, так и с участием представителей заповедника и туристических компаний, позволила оценить глубину возникающей неэффективности и скорость обучения участников.
\end{abstract}

Auction for Access Points Reservation in Reserved Areas: Theoretical and Experimental Research

Diana Avdeeva, Alexander Filatov

\section{Abstract}

The paper dwells upon developing an effective mechanism of interaction between the reserved areas and tour operators which allows to raise funds for priority projects, to involve new participants into the market and to create new tourism products for potential clients. The existing scheme of access points arrangement, hampering the new entrants, doesn't allow to realize the potential of ecological and educational tourism. The proposed mechanism, the principal element of which is the auction for the access points reservation, eliminates entry barriers, helps to redistribute quotas effectively, to raise money for the most important projects and investigations, and in general to solve the problem of inefficiency.

In particular, the reserved areas always have portfolios of tourism, environmental and scientific projects. At the same time

* Автор для связи: filatov.aiu@dvfu.ru

DOI: https://dx.doi.org/10.24866/2311-2271/2019-4/136-151 
the lack of the budget funding doesn't allow them to realize all of those projects. Besides, there is no reasonable experience of involving business into such issues solution.

The proposed mechanism allows the reserved areas to get funds from tour operators even for noncommercial projects. The firms supporting any of the projects financially (one or several, wholly or partly) become the partners of the reserved area. This is of interest for the partners not only for the purposes of advertising themselves or for improving their reputation.

Tour operators get the whole amount of the transferred money (and in some cases even some additional bonus) to their virtual accounts. They can spend these funds to buy permits for serving tourists on the top-requested routes.

The reserved areas offer some access points to be arranged (in the future all of them) by the auction. If a tour operator would like to enter the market or increase the number of available permits, it makes bids in the format $(p, q)$, i.e. the price and the corresponding number of tourists whom it is ready to serve at this price. The number of bids is unlimited. After the time expiration the access points are arranged by the multi-auction at the $(n+1)$-price (multi-version of the Vickrey auction). Access points are granted to the companies that have made the maximum bids.

It is possible to establish (by the decreasing coefficients) priorities in favor of certain companies, for example, long-term partners of the reserved areas, local tour operators, etc. This, in particular, can reduce skepticism regarding the transition to a new model of interaction between tour operators and the reserved areas. At the same time any other companies also have the opportunity to enter the market and receive the desired permits.

As for the important features of the auction format, determining its choice as the proposed mechanism, we can mention, that the auction shows the market price. This format allows to determine the real wish of the firm to pay for the tourism activities in the reserved areas. Indeed, it is at the Vickrey auction where each bidder could demonstrate its real demand. In addition, what is especially important for this format is a large number of permits and tour operators participating in the auction and that helps to solve the traditional issues of participants' collusion and possible auctioneer opportunism.

At the same time the agents irrational behavior can eliminate social effects of the auction. The pilot series of experiments performed involving students-economists as well as the representatives of the reserved areas and tourist companies allowed estimating the arising inefficiency and the learning rate. After updating the proposed mechanism is planned to be applied on the electronic platform of the recreational and tourist services developed at the FEFU together with the staff of the Kronotsky Biosphere Reserve. Upon successful testing, it can be adapted and applied in other protected areas.

\section{Введение}

Важное значение в охране окружающей среды занимают особо охраняемые природные территории [1]. Однако в настоящее время их потенциал, в том числе, в плане экологического и познавательного туризма, используется далеко не полностью. Это связано с тем, что собственных материальных и человеческих ресурсов не хватает, а нынешние партнеры слабо мотивированы на сотрудничество и раскрытие потенциала заповедника. Кроме того, система существующих ограничений чаще всего не позволяет решить эту проблему традиционным способом.

Необходимо предложить механизм, при котором, с одной стороны, соблюдались бы условия максимально возможного сохранения природных комплексов, а с другой, - обеспечивалась бы экономическая эффективность реализации рекреационно-познавательного потенциала заповедника.

Стоит сказать, что туристская деятельность соответствует задачам заповедника, к которым относится и экологическое просвещение, и развитие экологического туризма [2]. Последний будем понимать как «форму природоориентированного активного отдыха, осуществляемую с целью познания дикой природы, не нарушающую целостности экосистемы, а также призванную внести вклад в сохранение природных ресурсов, охрану окружающей среды и социально-экономическое развитие туристской территории» [3]. При этом доходы от экономической деятельности могут идти на природоохранные мероприятия, 
что укладывается в концепцию ресурсов общего пользования [4].

\section{Кроноцкий заповедник}

История образования особо охраняемых природных территорий (далее ООПТ) в России относится еще к петровским временам. К 2019 г. в России созданы 105 государственных природных заповедников, 52 национальных парка, 57 федеральных заказников, 17 федеральных памятников природы, а также более 12000 природных парков, заказников, памятников природы и других территорий, находящихся под защитой на региональном уровне [5].

Одной из территорий, обладающих наибольшим в России туристским потенциалом, является Кроноцкий биосферный заповедник. Он образован в 1934 г. на месте существовавшего с 1882 г. в юго-восточной части полуострова Камчатка Соболиного заповедника. Общая площадь заповедника составляет 1148 тыс. га, из которых наземные экосистемы занимают 1013 тыс. га, морская акватория - 135 тыс. га (рис. 1).

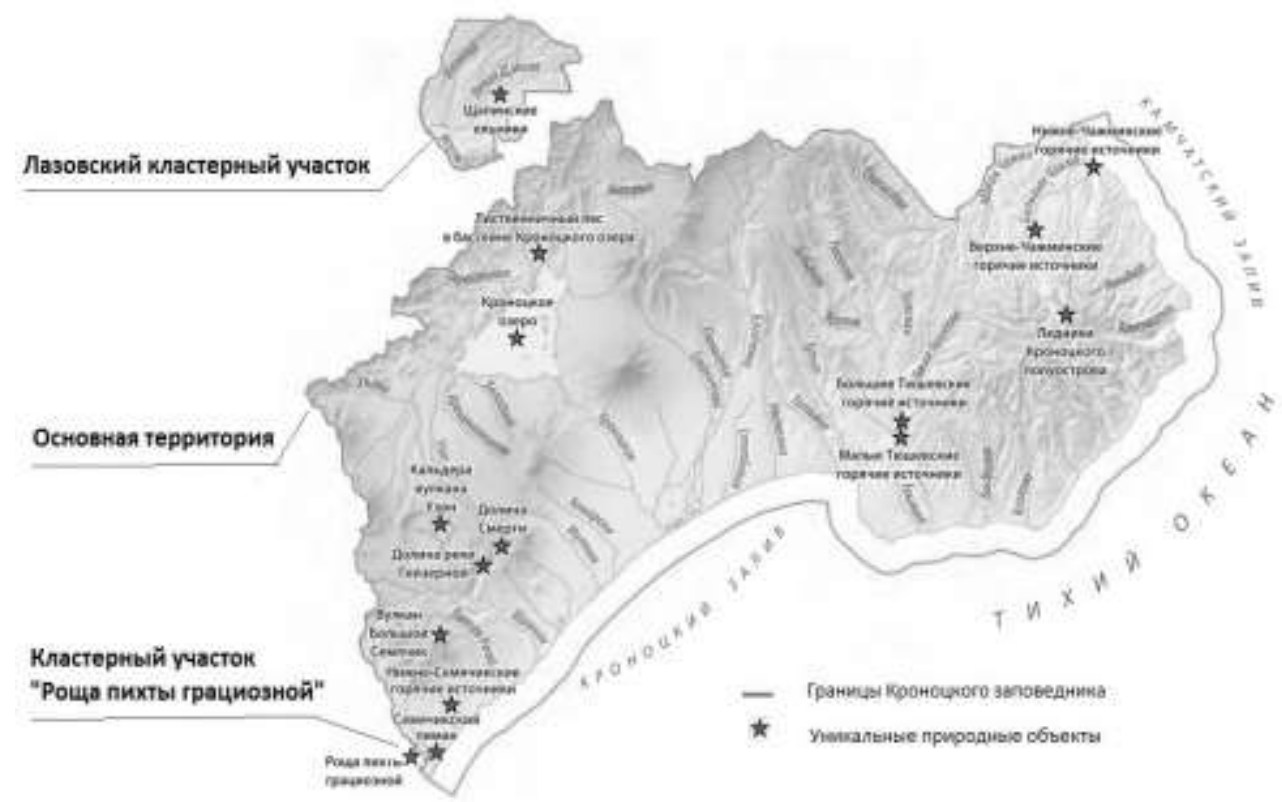

Рис.1. Обзорная схема Кроноцкого заповедника

Источник: составлено автором по [6]

Кроноцкий заповедник внесен в Список всемирного природного наследия ЮНЕСКО под общим названием «Вулканы Камчатки», и на его территории находятся такие всемирно известные достопримечательности, как долина Гейзеров, озеро Узон, долина Смерти. Если рассматривать туризм в заповеднике через призму рационального природопользования, то перед заповедником встает двуединая задача «сохранить, чтобы показать, и показать, чтобы сохранить», на которую и направлена его деятельность.

Из статистических данных видно, что спрос на заповедные маршруты, хоть и подвержен колебаниям, имеет устойчивую тенденцию к увеличению в среднем на $8 \%$ в год (рис. 2). 


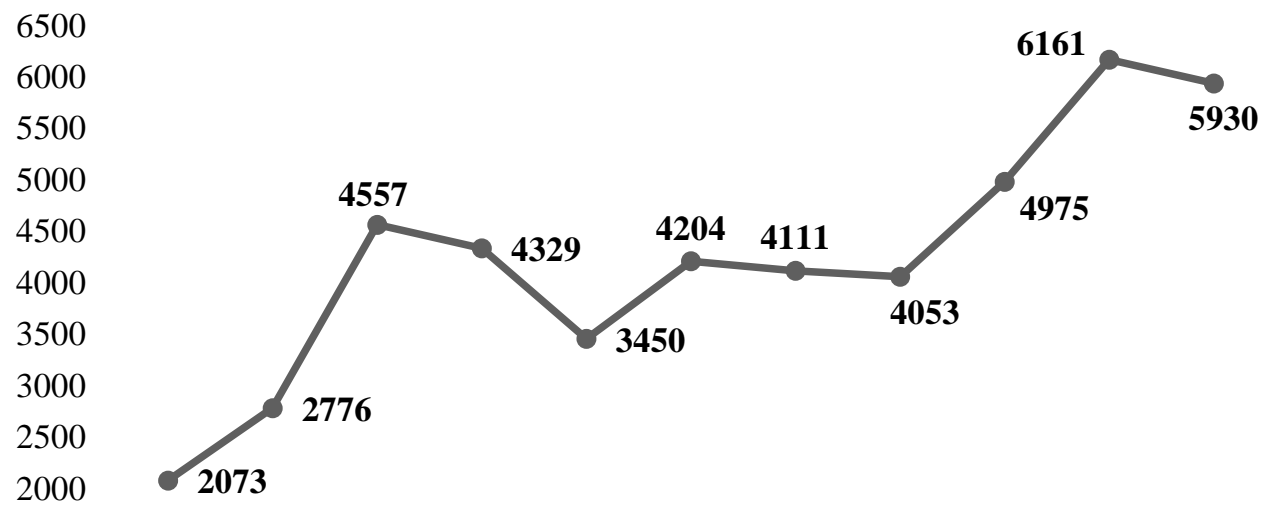

1500

$\begin{array}{lllllllllll}2007 & 2008 & 2009 & 2010 & 2011 & 2012 & 2013 & 2014 & 2015 & 2016 & 2017\end{array}$

Puc.2. Динамика посещений Кроноцкого заповедника, чел., 2007-2017 гг.

Источник: составлено авторами

Доля иностранных посетителей заповедника с каждым годом также увеличивается. Однако по-прежнему количество туристов, посещающих Кроноцкий заповедник, даже не в десятки, а в сотни раз уступает числу гостей его американского аналога - Йеллоустоунского национального парка. Несмотря на то, что Йеллоустоун не входит даже в пятерку наиболее посещаемых национальных парков США, в последние годы в него приезжают ежегодно более 4 млн человек. Конечно, столь масштабная туристская деятельность реализуется благодаря уникальной инфраструктуре этого первого в мировой истории национального парка, созданного еще в 1872 г. Две тысячи километров маркированных троп, сотни обзорных площадок, несколько оборудованных кемпингов - всё это создавалось десятилетиями при серьезном финансировании, как государственном, так и через дополнительные каналы, включая благотворительные фонды, а так-же поступления от экологического туризма.

К сожалению, Кроноцкий заповедник не может похвастаться аналогичными ресурсами. И это приводит к далеко не полному раскрытию его потенциал, что видно из озвученных цифр посещения, причем в сравнении не только с Йеллоустоунским национальным парком, но и с пиком советских времен, когда в 1970-80-е гг. сюда приезжало по 30 тыс. туристов.

\section{Текущий механизм взаимодействия заповедника и туроператоров}

На сегодняшний день у Кроноцкого заповедника заключены договоры на сотрудничество с 15 туроператорами и турагентами. Еще 21 фирма, занимающаяся турагентской и туроператорской деятельностью, в последние 5 лет выходила на связь, интересуясь возможностями туризма на территории заповедника. Однако несмотря на 36 потенциальных партнеров, только 8 туроператоров ведут на данный момент реальное обслуживание клиентов. Более того, внутри восьмерки также существует значительная дифференциация, и большинство мест распределяется между 3-4 туроператорами.

Причины сложившейся ситуации ясны. Если говорить о существующем механизме взаимоотношений, то сейчас нет четко обозначенных правил, которые были бы понятны всем участникам рынка. Чтобы получить разрешения на 
посещение заповедника туристами и экскурсантами (так называемые «места доступа»), турфирмы связываются с заповедником и бронируют свободные места посредством специальных форм. Создается ситуация, при которой, кто первый успел среагировать на изменение рынка, тот и получает квоты. Одновременно приоритет отдается тем турфирмам, которые давно и постоянно сотрудничают с заповедником и зарекомендовали себя. Таким образом, заповедник дает разрешение на посещение туристов и экскурсантов заповедных территорий, а за это получает некий официально не установленный процент прибыли. Также в договорах прописаны некоторые обязательства туроператоров и турагентов перед заповедником (например, перевозка грузов). Проблематичным является вход на рынок новых партнеров, поскольку типично все существующие места выкупаются на 2 года вперед, а прозрачных механизмов создания новых и перераспределения существующих мест не разработано.

Возникает замкнутый круг: отсутствие у заповедника средств на новые маршруты приводит к недостатку мест, из-за которого спрос на соответствующие услуги экологического туризма не покрывается, что лишает заповедник столь необходимых средств.

\section{Экологическая партнерская программа}

Авторами предлагается новый дизайн взаимодействия с туроператорами, построенный на схеме аукциона, позволяющий снизить существующие барьеры входа для новых партнеров, экономически эффективно перераспределять квоты, а также получить финансирование на актуальные исследования заповедника и создание новых туристических продуктов.

Начнем с последних. Обычно у заповедников есть портфель туристических, природоохранных и научных проектов (рис. 3).

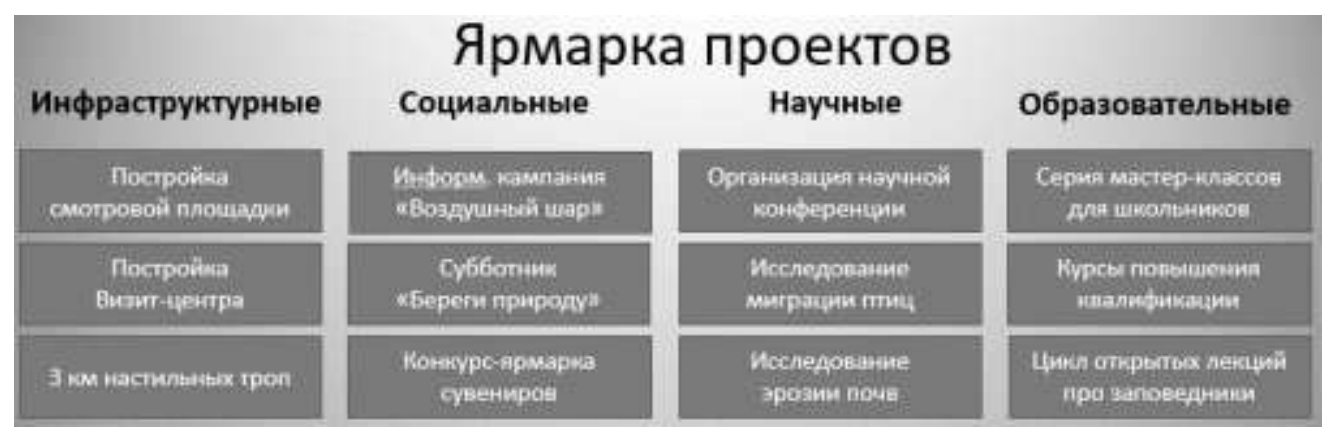

Рuc.3. Скриншот страница ярмарки проектов в электронной среде

Источник: составлено авторами

При этом государственного финансирования хватает далеко не всегда. Опыт привлечения бизнеса Кроноцким заповедником имеется, но носит точечный характер. В конце 1990-х гг. был реализован проект благоустройства туристической тропы со смотровыми площадками с учетом экологических, эстетических и психокомфортных факторов. Работы проводились по договору с акционерной компанией «Согжой», которая позже получила эксклюзивное право использования маршрута на правах аренды [2].

Предлагаемый дизайн расширяет данный механизм и позволяет запо- 
веднику получать от туроператоров финансирование не только на создаваемые туристические маршруты, но и другие проекты, включая научноисследовательские, напрямую не представляющие коммерческой ценности, ассоциируя ярмарку проектов с аукционом мест доступа.

Фирма, финансирующая любой из проектов (один или несколько, целиком или частично), вступает в экологическую партнерскую программу. При этом, в отличие от сегодняшней ситуации быть партнерам может быть интересно не только в рекламных целях или в целях улучшения имиджа, но и благодаря тому, что фирма получает на свой «виртуальный счет» все инвестированные средства, иногда даже с некоторым повышающим коэффициентом. Эти средства фирма может тратить на аукционе (следующем этапе механизма) для получения разрешений на обслуживание туристов на маршрутах, пользующихся высоким спросом.

Заметим, что данный механизм может быть использовать только если заповедник создал пользующийся повышенным спросом продукт, за обладание которым туроператоры готовы бороться и платить деньги. Создание такого продукта и повышение спроса на него - иные задачи, остающиеся за бортом нашего исследования. В то же время у Кроноцкого заповедника такой уникальный и дефицитный продукт сформирован, а значит механизм применим.

При этом заповедник может экономически стимулировать финансирование определенных приоритетных проектов. Как было сказано, все средства, вложенные в любые проекты, могут быть использованы для получения на аукционе желаемых мест доступа. А значит, для туроператора важна (внеэкономические причины инвестиций не принимаем во внимание) исключительно сумма на его виртуальном счете.

Следовательно, заповедник может при необходимости устанавливать для ряда проектов повышающие коэффициенты, например, 1,$01 ; 1,1 ; 1,2$ и т.д. В частности, вкладывая в проект с коэффициентом 1,1 сумму в 500 тыс. руб., туроператор получает на счет $500-1,1=550$ тыс. руб., от чего нет резона отказываться. Заметим, что особенно злоупотреблять повышающими коэффициентами заповеднику в данном варианте не следует. Рациональный туроператор будет инвестировать все средства в проекты с максимальным коэффициентом, а значит, уже уровня 1,01 будет достаточно, чтобы изменить его поведение желаемым образом.

Более интересная и важная для заповедника задача - попытаться ускорить инвестиции туроператоров, что, в частности, позволит в более ранние сроки реализовать проекты. В частности, если подготовка нового маршрута требует 5 млн руб., и хочется ее завершить к грядущему сезону, заповедник может дать повышающий коэффициент (скажем, 1,2) в случае полного покрытия расходов. Например, если к текущему моменту одна или несколько компаний вложили в данный проект в сумме 2 млн. руб., то туроператор, одномоментно инвестирующий еще 3 миллиона, получает на счет 3 млн 600 тыс. Это большой соблазн для туроператора, даже понимающего, что соответствующую сумму на аукционе он, возможно, будет использовать в течение нескольких лет. Ну а результат будет, в том числе, будет зависеть от размера туроператора (что определяет быстроту использования средств виртуального счета), а также его ставки дисконтирования.

Через систему априорных повышающих коэффициентов возможно так- 
же установление приоритетов в пользу определенных компаний - постоянных и давних партнеров, местных фирм, фирм, наиболее сильно помогающих в финансировании заповедника и т.д. Этим, в частности, можно сократить скепсис относительно перехода на новую модель взаимодействия существующих на рынке туроператоров и заповедника. В то же время, в отличие от нынешней ситуации, любые другие компании также имеют возможность получать желаемые разрешения.

\section{Аукцион разрешений на доступ в заповедник}

Итак, важным результатом вступления туроператора в экологическую партнерскую программу и участия в софинансировании проектов заповедника является некоторая сумма, накопленная им на виртуальном счете. Эту сумму туроператор может использовать в целях получения дополнительных мест доступа посредством аукциона, через который предполагается распределять часть разрешений на посещение заповедника.

Переход на новую систему предполагается осуществлять постепенно, чтобы выполнить обязательства перед существующими партнерами, а также позволить им некоторое время получать часть разрешений на привычных условиях, однако в перспективе на несколько лет планируется довести долю мест, распределяемых через аукцион, до 100\%.

Туроператоры, желающие войти на рынок или увеличить количество имеющихся разрешений, подают заявки в формате (цена, объем) - указывая, по какой цене они готовы обслужить какое количество туристов. Фактически этими заявками они задают собственную функцию спроса на каждый предлагаемый заповедником продукт. Количество заявок от каждого туроператора не ограничивается.

Пусть для $i$-туроператора, $i=1, \ldots, m$ заявки $\left(p_{i j}, q_{i j}\right), j=1, \ldots n_{i}$ отсортированы в порядке убывания цены и, соответственно, возрастания объемов. Тогда его индивидуальный спрос $q_{i}(p)$ является кусочно-линейной функцией, состоящей из горизонтальных участков вида:

$$
q_{i}(p)=\left\{\begin{array}{l}
0, \quad p_{i}>p_{i 1}, \\
q_{i j}, \quad p_{i} \in\left(p_{i(j+1)} ; p_{i j}\right], j=1, \ldots, n_{i}-1, \\
q_{i n_{i}}, \quad p_{i} \in\left[0 ; p_{i n_{i}}\right]
\end{array}\right.
$$

Суммарный рыночный спрос $Q(p)$ равен сумме индивидуальных:

$$
Q(p)=\sum_{i=1}^{m} q_{i}(p)
$$

После истечения заранее определенного срока экспирации, посредством мультиаукциона $(n+1)$-цены осуществляется распределение мест доступа в количестве $d$. Их получают компании, указавшие в заявках максимальные цены, в количестве, указанном в заявках.

Проиллюстрируем это на коротком примере. Пусть на рынке действуют два туроператора, заявки которых выглядят следующим образом: 


$$
\begin{array}{ll}
\text { Tyроператор 1: } & \text { Туроператор 2: } \\
p=1700, q=500 & p=2000, q=200 \\
p=1000, q=1000 & p=1500, q=450
\end{array}
$$

Пусть также заповедник распределяет через аукцион 1000 разрешений. Заметим, что этих мест не хватает для удовлетворения имеющегося спроса. Аукцион действует подобно потребителю в супермаркете, который при ограниченном бюджете поочередно складывает в корзину товары, приносящие ему максимальную полезность в расчет.

Второй туроператор, готовый заплатить по 2000 руб. за 200 мест, сразу получает их. Далее первый туроператор получает 500 мест, т.к. готов заплатить за них по 1700 руб. Туроператор 2 (готовый заплатить по 1500 руб.) получает еще 250 мест (суммарно 450). Наконец, туроператор 1 забирает оставшиеся 50 мест. Итого, у первого туроператора оказывается 550 мест из 1000, на которые тот предъявляет спрос, а второй получает все требующиеся ему 450 разрешений.

При этом оба туроператора платят за доступ к каждому из полученных мест одинаковую сумму, а именно 1000 руб., цену отсечения, в которую обходится следующее 1001-е место. В связи с этим при наличии богатого VIPклиента, готового очень дорого заплатить за посещение заповедника, туроператор может не бояться делать заявку, скажем, на одно место за 100 тыс. руб., понимая, что в реалистической ситуации достаточного количества мест он все равно заплатит относительно немного, однако благодаря высокой заявке получит гарантию получения места в любой ситуации.

Рассмотрим чуть более сложный случай, предположив, что в рассмотренном выше примере первый туроператор готов выкупить 1000 мест не по 1000, а по 1500 руб., что совпадает с заявкой его конкурента. Заметим, что на распределение первых 700 мест (200 второму и 500 первому) это никак не повлияет. А оставшиеся 300 мест должны быть в некоторой пропорции распределены между первым и вторым туроператором. При этом спрос первого туроператора $(1000-500=500$ мест) оказывается вдвое больше спроса второго (450 $200=250$ мест). Поэтому логично, что первый туроператор получит дополнительных мест вдвое больше второго (200 против 100), а в итоге 700 мест достанется первому туроператору и 300 мест - второму. Все места будут проданы по цене отсечения в 1500 руб.

\section{Причины использования аукциона}

Аукционы за последние полвека из маргинальной области экономики, известной публике исключительно благодаря продажам произведений искусства, превратились в наиболее явную историю успеха приложения теоретических конструкций экономики к практике. Краткий нетехнический обзор теории аукционов дан в [7], более подробное изложение темы представлено в учебнике [8] и обзоре статей [9].

Среди важных свойств аукциона, определивших его выбор в качестве предложенного механизма, можно выделить то, что аукцион формирует цену. Как уже говорилось, целью данного механизма является не изменение спроса или предложения на рынке туристических услуг, а повышение экономической эффективности этого рынка, в частности, установление на нем равновесной цены, уравнивающих спрос и предложение и обеспечивающей наибольшие продажи. При этом реальный рынок на данный момент находится вне равновесия. 
Заниженная цена (в экспериментах в качестве примера была взята цена $c=6400$ руб. на одну из наиболее популярных экскурсий «Царство нерки и бурого медведя») приводит к дефициту мест, и существенному недополучению средств заповедником. В то же время, чрезмерное повышение цены может, напротив, привести к серьезному сокращению объема продаж и даже доходов заповедника. Поскольку заповедник обычно слабо представляет себе спрос, который предъявляют неоднородные туроператоры, работающие на различных сегментах рынка, а быстрое нащупывание оптимальной цены, как это происходит с большинством потребительских товаров, здесь невозможно, то выявление равновесной цены является нетривиальной задачей. И именно эту задачу призван решить аукцион, поскольку цена формируется в нем непосредственно в результате торгов.

Вторым важным аспектом аукциона является то, что он повышает экономическую эффективность рынка, передавая места доступа туроператорам, которые в состоянии заплатить больше. Конечно, существуют и внеэкономические причины, по которым в некоторых случаях часть мест должна передаваться определенной группе приоритетных посетителей. Но этот вопрос - неэкономического плана, и его решение (как правило директивное при активном участии государства) остается за бортом нашего исследования.

Очень важным вопросом, определяющим как стратегии участников, так и получаемые результаты, является формат аукциона. Среди форматов, использующихся для стандартных аукционов, особую роль играет закрытый аукцион второй цены, также называемый аукционом Викри. Как и в аукционе первой цены, каждый его участник однократно подает заявку, аукционист отдает лот указавшему максимальную сумму. Однако победитель платит не указанную им цену, а вторую по величине, то есть максимальную из цен, указанных конкурентами.

Казалось бы, очень странное решение собирать с победителя меньше, чем тот готов заплатить. Но это только на первый взгляд - ведь изменение дизайна аукциона приводит к изменению стимулов. И достаточно легко доказать, что доминирующей стратегией поведения для каждого участника будет стратегия «называть свою собственную оценку лота». Действительно, при завышении цены участник рискует переплатить, если заявка кого-то из конкурентов попадет в диапазон между его ценностью и заявкой. Напротив, при занижении риск состоит в проигрыше аукциона - в ситуации, когда цена кого-то из конкурентов попадет в диапазоне между ценностью и заявкой потенциального победителя, тот проигрывает аукцион, хотя мог бы получить положительные прибыли.

Представленный в предыдущем параграфе формат аукциона является обобщением аукциона Викри на случай распределения большого числа однородных лотов. И при наличии конкуренции нескольких туроператоров оптимальной стратегией каждого из них является честная демонстрация монопольного выпуска на собственном фактическом спросе. Поэтому данный формат (и это еще одно его полезное свойство!) позволяет определить истинную ценность разрешений и узнать, какую сумму готовы заплатить туроператоры за туристическую деятельность в заповеднике. Кроме того, что особенно важно, при большом количестве участников аукциона и распределяемых между ними мест доступа исчезает традиционные для аукциона Викри проблемы возможного сговора участников и оппортунизма аукциониста.

В то же время, нерациональное поведение туроператоров во время аук- 
циона (связанное, в том числе, с непривычным для них форматом) может нивелировать общественный выигрыш от его внедрения [10]. Поэтому в течение 2019 года была проведена пилотная серия экспериментов с участием как студентов-экономистов, так и представителей туристического бизнеса, приехавших на международный туристский форум в ДВФУ. Эти эксперименты были призваны, в частности, оценить глубину возникающей неэффективности.

\section{Экспериментальное исследование аукциона}

Эксперимент заключался в следующем: каждому из 9 его участников, имитирующих представителей 9 туроператоров, на вход подавались индивидуальная функция спроса (в формате 10 точек «ретроспективных продаж») с определенным случайным отклонением. Имитировались фирмы разного размера с высоким или низким, элитным или массовым спросом. В качестве усложненной вариации также можно подавать спрос в динамике, например, возрастающий со временем. Пример подаваемых на вход исходных данных представлен в табл. 1 и на рис. 4.

Таблица 1

Индивидуальный спрос, подаваемый на вход участнику эксперимента

\begin{tabular}{|c|c|c|c|c|c|c|c|c|c|c|}
\hline Цена & 11567 & 12053 & 14286 & 13974 & 12320 & 15168 & 11743 & 11179 & 11142 & 11295 \\
\hline Объем продажс & 409 & 402 & 348 & 336 & 439 & 341 & 459 & 484 & 481 & 469 \\
\hline
\end{tabular}

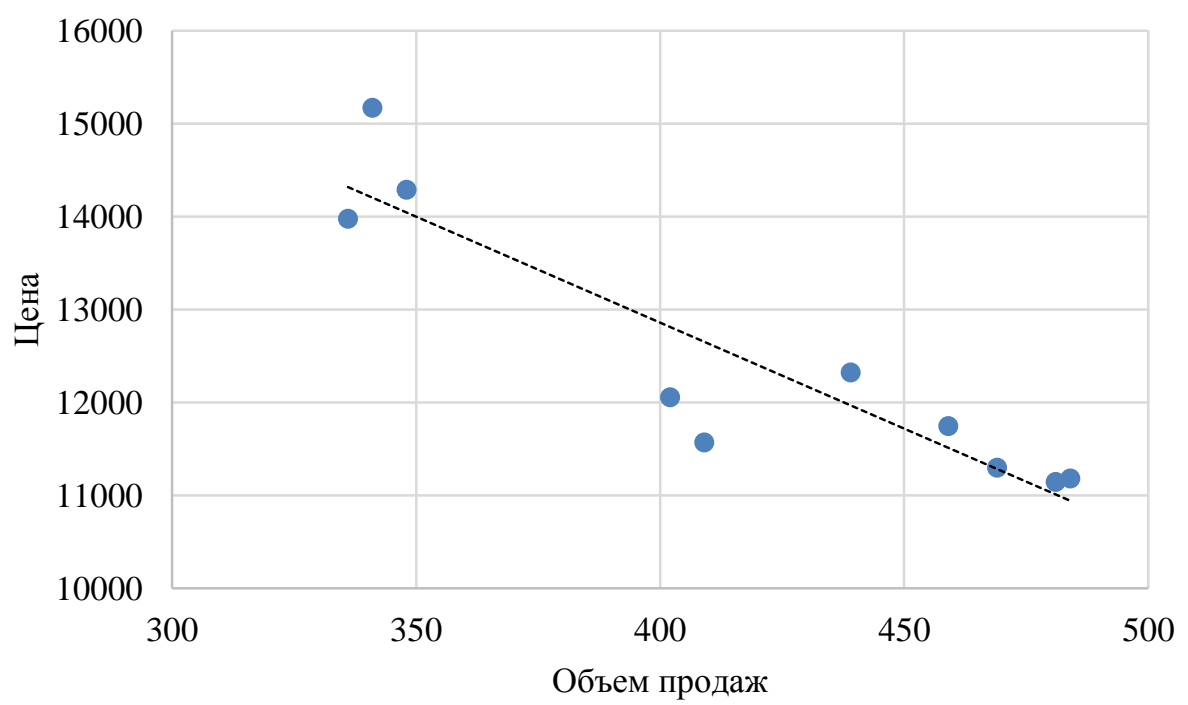

Puc.4. Индивидуальный спрос, подаваемый на вход участнику эксперимента

Источник: составлено авторами

Также участникам эксперимента сообщалось суммарное число мест доступа, равное в экспериментах 1000. При этом суммарный спрос при нулевой цене за разрешение (базовую сумму в 6400 руб. за обслуживание туриста в заповеднике в любом случае потребуется заплатить) был в экспериментах примерно в 2,5 раза выше - около 2500.

На основе полученной информации участники подавали заявки - какую дополнительную цену сверх базовой цены заповедника, они готовы заплатить 
за каждое число мест доступа. Как мы говорили в предыдущем разделе, оптимальной стратегией поведения является честная подача монопольного выпуска на указанном спросе. При линейности спроса и неизменности предельных издержек (эти условия в эксперименте выполнялись) монопольный выпуск составляет половину от фактического спроса.

Например, при цене 11 тыс. (что означает готовность туроператора дополнительно к 6400 руб. доплатить за место доступа еще 4600 руб.) фактический спрос составляет примерно 480 посещений, а значит, монополист захочет для максимизации своей прибыли по монопольной цене около 18500 руб. продать 240 туров в «Царство нерки и бурого медведя». Т.е. одной из заявок могла стать заявка (4600 руб.; 240 мест). И таких заявок могло быть много с целью наилучшей аппроксимации монопольного выпуска в зависимости от цены места доступа.

После подачи заявок всеми участниками эксперимента места доступа разыгрывались на аукционе, сообщались результаты, и на втором этапе каждый из участников, получивших положительное число мест, должен был указать, по какой цене он собирается продавать своим клиентам данный тур в заповедник.

\section{Некоторые результаты экспериментов}

Представим далее некоторые результаты пилотного экспериментального исследования. Начнем с первого из экспериментов, проведенного на магистрантах 1 курса программы «Государственное и муниципальное управление» ШЭМ ДВФУ. В его рамках между участниками аукциона возникла очень жесткая конкуренция, итогом которой стала цена доступа 7000 руб. Это привело к росту дохода заповедника от одного туриста более, чем вдвое, с первоначального уровня в 6400 руб. до значения $6400+7000=13400$ руб. Таким образом, аукцион помог предоставить заповеднику серьезный дополнительный ресурс, в том числе, на развитие экологического туризма.

Более детально оценим итоги для туроператоров. В табл.2 приведена информация о доставшихся им местам (все, кроме последних двух фирм, которые сделали слишком низкие заявки и остались без разрешений, места получили). Здесь же дано сравнение по ценам, выручке, издержкам и прибыли туроператоров в ситуации, которая реализовалась в процессе эксперимента, и в той, которая была бы оптимальной на втором этапе выбора цен.

В частности, видим, что фирмы 3,5 и 7 боролись на аукционе излишне жестко, получили избыточные места доступа и не смогли их реализовать по желаемой цене и при существующем спросе. При этом туроператоры 3 и 7 могли привлечь клиентов скидками (и это было для них оптимально в сложившихся условиях), пятый же по причине низкого спроса в эконом-сегменте в принципе не мог исправить последствия неверной политике на этапе аукциона и выйти из зоны убытков. Остальные 4 туроператора, столкнувшиеся с дефицитом мест, напротив, могли незначительно повысить цены. Впрочем, эксперимент показал, что устанавливать оптимальную цену его участники умеют гораздо лучше, нежели подавать заявки на аукционе.

В то же время практически все участники эксперимента после оглашения его результатов поняли свои ошибки и пожелали подкорректировать свои стратегии на первой фазе - аукционе. В табл.3 сведем результаты, которые бы были получены, если бы все туроператоры вели себя рационально в процессе аук- 
циона. А, как мы помним, рациональное поведение туроператора здесь предполагает честную подачу своего монопольного предложения.

Таблииа 2

Полученные по итогам аукциона места, цена тура, объем продаж и прибыль туроператоров

\begin{tabular}{|l|c|c|c|c|c|c|c|c|c|c|}
\hline & Уч.1 & Уч.2 & Уч.3 & Уч.4 & Уч.5 & Уч.6 & Уч.7 & Уч.8 & Уч.9 \\
\hline Цена отсечения, руб. & \multicolumn{8}{|c|}{7000} \\
\hline Полученные места, шт. & 250 & 60 & 200 & 150 & 80 & 100 & 160 & 0 & 0 \\
\hline
\end{tabular}

Реализовавшееся по итогам результатов аукциона поведение

\begin{tabular}{|l|c|c|c|c|c|c|c|c|c|}
\hline Цена тура, тыс.руб. & 17 & 22 & 17 & 22 & 13 & 19,54 & 15 & - & - \\
\hline Объем продаж, шт. & 250 & 60 & 161 & 150 & 49 & 100 & 105 & 0 & 0 \\
\hline Избыточные места, шт. & - & - & 39 & - & 31 & - & 55 & - & - \\
\hline Выручка, тыс. руб. & 4250 & 1320 & 2737 & 3300 & 637 & 1954 & 1575 & 0 & 0 \\
\hline Издержки, тыс. руб. & 1600 & 384 & 1030 & 960 & 314 & 640 & 672 & 0 & 0 \\
\hline Доступ к турам, тыс. руб. & 1750 & 420 & 1400 & 1050 & 560 & 700 & 1120 & 0 & 0 \\
\hline Прибыль, тыс. руб. & 900 & 516 & 307 & 1290 & -237 & 614 & -217 & 0 & 0 \\
\hline
\end{tabular}

\begin{tabular}{|l} 
Прибыль, тыс. руб. \\
Оптимальное по итогам результатов аукциона поведение \\
\hline
\end{tabular}

\begin{tabular}{|l|c|c|c|c|c|c|c|c|c|}
\hline Опт. цена тура, тыс. руб. & 17,8 & 22,4 & 15,5 & 23,5 & 12,7 & 23,3 & 13,5 & - & - \\
\hline Изменение, тыс. руб. & 0,8 & 0,4 & $-1,5$ & 1,5 & $-0,3$ & 3,8 & $-1,5$ & - & - \\
\hline Опт. обьем продаж, шт. & 250 & 60 & 200 & 150 & 51 & 100 & 160 & 0 & 0 \\
\hline Избыточные места, шт. & - & - & - & - & 29 & - & - & - & - \\
\hline Прибыль, тыс. руб. & 1100 & 539 & 424 & 1508 & -237 & 989 & 19 & 0 & 0 \\
\hline Изменение, тыс. руб. & 200 & 23 & 118 & 218 & 0 & 375 & 236 & 0 & 0 \\
\hline
\end{tabular}

Источник: составлено авторами

Как нетрудно увидеть, при оптимальном поведении туроператоров цена отсечения бы снизилась с 7000 до 5506 руб., при этом все они получили бы определенное число мест (первый, третий, пятый и седьмой в меньшем количестве, остальные - в большем). Суммарные прибыли туроператоров из-за неверной стратегии на первой стадии (аукционе) упали с 7 млн 273 тыс. руб. до 4 млн 342 тыс. руб., то есть на 40\%. Неточное поведение на второй стадии (при выборе цены) дало падение прибылей еще на 16\% до 3 млн 173 тыс. руб. (именно это значение мы наблюдали в эксперименте). Обучение в состоянии сократить эти потери туроператоров.

Таблица 3

Оптимальное поведение туроператоров на аукционе

\begin{tabular}{|l|c|c|c|c|c|c|c|c|c|c|c|}
\hline & Уч.1 & Уч.2 & Уч.3 & Уч.4 & Уч.5 & Уч.6 & Уч.7 & Уч.8 & Уч.9 \\
\hline Цена отсечения, руб. & \multicolumn{9}{|c|}{5506} \\
\hline Полученные места, шт. & 214 & 61 & 148 & 153 & 29 & 115 & 110 & 58 & 112 \\
\hline Изменение, шт. & -36 & 1 & -52 & 3 & -51 & 15 & -50 & 58 & 112 \\
\hline Опт. цена тура, тыс. руб. & 19,0 & 22,2 & 17,5 & 23,2 & 15,4 & 22,0 & 14,9 & 25,5 & 13,6 \\
\hline Изменение, тыс. руб. & 1,2 & $-0,2$ & 2,0 & $-0,3$ & 2,7 & $-1,3$ & 1,4 & - & - \\
\hline Прибыль, тыс. руб. & 1516 & 629 & 827 & 1733 & 102 & 1159 & 327 & 789 & 191 \\
\hline Изменение, тыс. руб. & 416 & 90 & 403 & 225 & 340 & 170 & 308 & 789 & 191 \\
\hline
\end{tabular}

Источник: составлено авторами

В качестве последнего, четвертого, сценария рассмотрим нормативное распределение мест между 4 крупнейшими туроператорами в соотношении $40 \%, 30 \%, 20 \%$ и $10 \%$, что достаточно неплохо аппроксимирует реальность и, более того, является одним из наиболее эффективных нормативных вариантов распределения. Предположим также оптимальное ценообразование данных че- 
тырех туроператоров. Представим результаты в случае реализации всех рассмотренных сценариев их поведения в табл.4.

Таблица 4

Сопоставление результатов туроператоров на аукционе

\begin{tabular}{|c|c|c|c|c|c|c|c|c|c|}
\hline & Уч.1 & Уч.2 & Уч.3 & Уч.4 & Уч.5 & Уч.6 & Уч.7 & Уч.8 & Уч.9 \\
\hline \multicolumn{10}{|c|}{ Влияние на цены } \\
\hline Оптимальная, тыс. руб. & 19,0 & 22,2 & 17,5 & 23,2 & 15,4 & 22,0 & 14,9 & 25,5 & 13,6 \\
\hline Оптим., стадия 2, тыс. руб. & 17,8 & 22,4 & 15,5 & 23,5 & 12,7 & 23,3 & 13,5 & - & - \\
\hline Реальная, тыс. руб. & 17 & 22 & 17 & 22 & 13 & 19,5 & 15 & - & - \\
\hline Без аукциона, тыс. руб. & 16,1 & - & 19,3 & - & - & - & 12,4 & - & 9,2 \\
\hline Отклонение стадии 2, \% & $-6,3$ & 0,9 & $-11,4$ & 1,3 & $-17,5$ & 5,9 & $-9,4$ & - & - \\
\hline Реальное отклонение, \% & $-10,5$ & $-0,9$ & $-2,9$ & $-5,2$ & $-15,6$ & $-11,2$ & 0,7 & - & - \\
\hline Отклонение без аукц., \% & $-15,3$ & - & 10,3 & - & - & - & $-16,8$ & - & $-32,4$ \\
\hline \multicolumn{10}{|c|}{ Влияние на объемы продаж } \\
\hline Оптимальный, шт. & 214 & 61 & 148 & 153 & 29 & 115 & 110 & 58 & 112 \\
\hline Оптим., стадия 2, шт. & 250 & 60 & 200 & 150 & 51 & 100 & 160 & 0 & 0 \\
\hline Реальный, шт. & 250 & 60 & 161 & 150 & 49 & 100 & 105 & 0 & 0 \\
\hline Без аукциона, шт. & 300 & 0 & 100 & 0 & 0 & 0 & 200 & 0 & 400 \\
\hline Отклонение стадии 2, \% & 17 & -2 & 35 & -2 & 76 & -13 & 45 & -100 & -100 \\
\hline Реальное отклонение, \% & 17 & -2 & 9 & -2 & 69 & -13 & -5 & -100 & -100 \\
\hline Отклонение без аукц., \% & 40 & -100 & -32 & -100 & -100 & -100 & 82 & -100 & 257 \\
\hline \multicolumn{10}{|c|}{ Влияние на прибыли } \\
\hline Оптимальная, тыс. руб. & 1516 & 629 & 827 & 1733 & 102 & 1159 & 327 & 789 & 191 \\
\hline Оптим., стадия 2, тыс. руб. & 1100 & 539 & 424 & 1508 & -237 & 989 & 19 & 0 & 0 \\
\hline Реальная, тыс. руб. & 900 & 516 & 307 & 1290 & -237 & 614 & -217 & 0 & 0 \\
\hline Без аукциона, тыс. руб. & 2925 & 0 & 1292 & 0 & 0 & 0 & 1207 & 0 & 1137 \\
\hline Отклонение стадии 2, \% & -27 & -14 & -49 & -13 & -332 & -15 & -94 & -100 & -100 \\
\hline Реальное отклонение, \% & -41 & -18 & -63 & -26 & -332 & -47 & -166 & -100 & -100 \\
\hline Отклонение без аукц., \% & 93 & -100 & 56 & -100 & -100 & -100 & 269 & -100 & 495 \\
\hline
\end{tabular}

Источник: составлено авторами

\section{Сопоставление 4 моделей поведения участников аукциона}

Заметим, что привилегированные компании, получающие большое количество мест доступа без аукциона, типично (хоть и не всегда) теряют в прибылях. Однако, как показывает табл.5, агрегирующая информацию о прибылях разных взаимодействующих сторон, даже туроператоры в совокупности могут выиграть в результате более эффективного перераспределения мест доступа. Как мы видим, при директивном распределении мест суммарная прибыль туроператоров составляет 6 млн 651 тыс. руб., а при аукционе в случае их оптимального поведения - 7 млн 273 тыс. руб.

Действительно, привилегированные туроператоры типично теряют места (впрочем, третий туроператор, которому было положено 100 мест, благодаря аукциону увеличил свою долю на рынке почти в 1,5 раза) и вынуждены платить за них на общих основаниях. Однако другие, зачастую более эффективные, туроператоры получают благодаря аукциону возможность выходить на рынок, предлагать свои услуги и получать прибыли. И выигрыш новичков, как мы видим, превосходит потери привилегированных фирм.

При этом доходы заповедника возрастают куда более существенно. Действительно, возможные потери туроператоров связаны с тем, что раньше места доступа им доставались бесплатно, а теперь они должны платить. Но их расхо- 
ды - это доходы заповедника. А значит, общество гарантированно выигрывает от реализации данного механизма. В данном примере почти вдвое.

Таблииа 5

Сопоставление разных моделей по полученным прибылям Эксперимент 1

\begin{tabular}{|l|c|c|c|}
\hline \multicolumn{1}{|c|}{ Модель } & Туропер. & Заповед. & Сумма \\
\hline Аукцион, оптимальное поведение & 7273 & 5506 & 12779 \\
\hline Аукцион, оптимальное ценообразование & 4342 & 7000 & 11342 \\
\hline Аукцион, реальное поведение & 3173 & 7000 & 10173 \\
\hline Отсутствие аукциона, оптим. ценообраз. & 6561 & 0 & 6561 \\
\hline
\end{tabular}

Источник: составлено авторами

Заметим, что практическая реализация аукциона может быть разной. На одном из экспериментов, проведенных среди студентов, цена отсечения составила всего 2500 руб. (табл.6). А представители туристического бизнеса, попытавшиеся сэкономить, и вовсе получили все разрешения по минимальной из указанных цен - по 1 руб. (табл.7).

Таблица 6

Сопоставление разных моделей по полученным прибылям. Эксперимент 2

\begin{tabular}{|l|c|c|c|}
\hline \multicolumn{1}{|c|}{ Модель } & Туропер. & Заповед. & Сумма \\
\hline Аукцион, оптимальное поведение & 7273 & 5506 & 12779 \\
\hline Аукцион, оптимальное ценообразование & 6282 & 2500 & 8782 \\
\hline Аукцион, реальное поведение & 5226 & 2500 & 7726 \\
\hline Отсутствие аукциона, оптим. ценообраз. & 6561 & 0 & 6561 \\
\hline
\end{tabular}

Источник: составлено авторами

Таблица 7

Сопоставление разных моделей по полученным прибылям. Эксперимент 3

\begin{tabular}{|l|c|c|c|}
\hline \multicolumn{1}{|c|}{ Модель } & Туропер. & Заповед. & Сумма \\
\hline Аукцион, оптимальное поведение & 7273 & 5506 & 12779 \\
\hline Аукцион, оптимальное ценообразование & 8714 & 1 & 8715 \\
\hline Аукцион, реальное поведение & 7306 & 1 & 7307 \\
\hline Отсутствие аукциона, оптим. ценообраз. & 6561 & 0 & 6561 \\
\hline
\end{tabular}

Источник: составлено авторами

Следует отметить, что, одновременно ведя себя нерационально в процессе третьего эксперимента, туроператоры даже увеличили свои прибыли с 7 млн 273 тыс. руб. до 8 млн 714 тыс. руб. Неточное поведение на второй стадии уменьшило прибыли до 7 млн 306 тыс. руб., однако даже эта величина превосходила исходный индивидуально рациональный уровень. Однако сложившаяся ситуация равновесием не является - практически все фирмы могли существенно увеличить свою долю на рынке, указав в заявке цену всего в 2 руб., и именно таким было желание большинства участников эксперимента после объявления итогов аукциона. То есть эти большие прибыли были получены за счет ошибок конкурентов.

Теоретически можно бы было рассмотреть кооперативное поведение участников рынков, когда они, сговорившись, откажутся делать высокие заявки на аукционе. В то же время, как отлично известно из теории организации рынков, этот сговор не является устойчивым, и его очень сложно со- 
хранить даже без вмешательства государства. Особенно большие риски накладывает возможность входа на рынок неограниченного круга новых туроператоров, которые в случае сговора могут малой кровью завоевать значимую долю рынка.

С высокой вероятностью при следующем аукционе никто не захочет повторять своих ошибок, а значит, ситуация будет сходиться к равновесию, которое соответствует верхним строкам табл. 5-7 и индивидуально рациональному поведению участников аукциона. Такие выводы, в частности, можно сделать на основе обсуждения результатов эксперимента с его участниками и анализа тех корректив, которые они хотели бы внести в свои стратегии поведения. Более строгий эксперимент, позволяющий количественно оценить скорость обучения (в т.ч. с использованием демонстрационной версии системы), предполагается осуществить в ближайшее время.

При этом, справедливости ради, заметим, что даже реализовавшаяся неравновесная ситуация, в которой заповедник не получает практически ничего, благодаря перераспределению мест доступа оказывается эффективнее нормативного распределения мест доступа, которое, по сути, реализуется в настоящее время.

Предлагаемый механизм планируется реализовать на специально создаваемой электронной платформе рекреационно-туристических услуг, разрабатываемой на базе ДВФУ совместно с сотрудниками Кроноцкого биосферного заповедника. При успешной апробации его можно адаптировать и применить в других ООПТ.

\section{Список источников / References}

1. Федеральный закон о об особо охраняемых природных территориях от 14.11.1996 №132-Ф3. [Federal`ny`j zakon o ob osobo oxranyaemy`x prirodny`x territoriyax [Federal Law on Protected Areas]. 14.11.1996 no. 132-FZ.]

2. Чижова В.П. Допустимые рекреационные нагрузки в охраняемых природных территориях Камчатки. География и туризм, 2006, сc. 239-253. [Chizhova V.P. Dopustimy`e rekreacionny`e nagruzki v oxranyaemy`x pri-rodny`x territoriyax Kamchatki [Permissible recreational loads in protected natural areas of Kamchatka]. Geografiya $i$ Turizm $=$ Geography and Tourism, 2006, pp. 239-253.]

3. Лапочкина В.В., Косарева Н.В., Адашова Т.А. Экологический туризм в России: тенденции развития. Международный научно-исследовательский журнал, 2016, №5 (47), cc.100-105. [Lapochkina V.V., Kosareva N.V., Adashova T.A. E`kologicheskij turizm v Rossii: tendencii razvitiya [Ecotourism in Russia: development trends]. Mezhdunarodny`j nauchno-issledovatel'skij zhurnal = International Research Journal, 2016, no. 5 (47), pp.100-105.]

4. Жильцов Е.Н., Казаков В.Н. Экономика социальных отраслей сферы услуг. Москва, ТЕИС, 2007. 288 c. [Zhil`czov E.N., Kazakov V.N. E`konomika social`ny`x otraslej sfery` uslug [Economics of social services industries]. Moscow, TEIS Publ., 2007. 288 p.]

5. Информационно-справочная система ООПТ [Informacionno-spravochnaya sistema OOPT [Protected area Reference System]. Available at: http://oopt.info

6. Завадская А.В., Николаева Е.А., Сажина В.А. Экономическая оценка природных ресурсов и экосистемных услуг Кроноцкого заповедника и Южно-Камчатского заказника. Петропавловск-Камчатский, Камчатпресс, 2017. 244 с. [Zavadskaya A.V., Nikolaeva E.A., Sazhina V.A. E`konomicheskaya ocenka prirodny`x resursov i e`kosistemny`x uslug Kronoczkogo zapovednika i Yuzhno-Kamchatskogo zakaznika [Economic assessment of natural resources and ecosystem ser-vices of the Kronotsky re- 
serve and the South Kamchatka reserve]. Petropavlovsk-Kamchatsky, Kamchatpress Publ., 2017. 244 p.]

7. Савватеев А.В., Филатов А.Ю. Теория и практика аукционов. Вестник ВГУ: экономика и управление, 2018, №3, сс. 119-131. [Savvateev A.V., Filatov A.Yu. Teoriya i praktika aukcionov [Theory and Practice of Auctions]. Vestnik VGU: e`konomika $i$ upravlenie $=$ Bulletin of Voronezh State University: Economics and Management, 2018, no. 3, pp. 119-131.]

8. Krishna V. Auction theory. Academic press, 2009. $336 \mathrm{p}$.

9. Klemperer P. Auction theory: a guide to the literature. Journal of Economic Surveys, 1999, №3 (13), pp. 227-286.

10. Hendricks K., Porter R. An empirical perspective on auctions. Handbook of Industrial Organization, 2007, vol. 3, pp.2073-2143.

\section{Сведения об авторах / About authors}

Авдеева Диана Владимировна, магистрант кафедры экономики предприятия, Школа экономики и менеджмента, Дальневосточный федеральный университет. 690922 Россия, г. Владивосток, о-в Русский, кампус ДВФУ, корпус G. E-mail: avdeeva.dv@students.dvfu.ru

Diana V. Avdeeva, Master Student of the Department of Enterprise Economics, School of Economics and Management, Far Eastern Federal University. Building G, FEFU campus, Russky Island, Vladivostok, Russia690922.E-mail:avdeeva.dv@students.dvfu.ru

Филатов Александр Юрьевич, кандидат физико-математических наук, доцент, доцент Департамента экономических наук, научный руководитель Научно-исследовательской лаборатории моделирования социально-экономических процессов, Школа экономики и менеджмента, Дальневосточный федеральный университет. 690922 Россия, г. Владивосток, о-в Русский, кампус ДВФУ, корпус G, каб. G335. E-mail: filatov.aiu@dvfu.ru

Aleksander Yu. Filatov, Candidate of Physical and Mathematical Sciences, Associate Professor, the Department of Economic Sciences, Scientific Director, the Research Laboratory of Modeling SocioEconomic Processes, School of Economics and Management, Far Eastern Federal University. Office G335, building G, FEFU campus, Russky Island, Vladivostok, Russia 690922.

E-mail: filatov.aiu@dvfu.ru 